\title{
The Alternative Route to Heme in the Methanogenic Archaeon Methanosarcina barkeri
}

\author{
Melanie Kühner, ${ }^{1}$ Kristin Haufschildt, ${ }^{1}$ Alexander Neumann, ${ }^{2}$ Sonja Storbeck, ${ }^{1}$ \\ Judith Streif, ${ }^{1}$ and Gunhild Layer ${ }^{1}$ \\ ${ }^{1}$ Institut für Mikrobiologie, Technische Universität Braunschweig, Spielmannstr 7, 38106 Braunschweig, Germany \\ ${ }^{2}$ Institut für Organische Chemie, Technische Universität Braunschweig, Hagenring 30, 38106 Braunschweig, Germany \\ Correspondence should be addressed to Gunhild Layer; g.layer@tu-braunschweig.de
}

Received 12 August 2013; Accepted 25 October 2013; Published 23 January 2014

Academic Editor: William B. Whitman

Copyright (C) 2014 Melanie Kühner et al. This is an open access article distributed under the Creative Commons Attribution License, which permits unrestricted use, distribution, and reproduction in any medium, provided the original work is properly cited.

\begin{abstract}
In living organisms heme is formed from the common precursor uroporphyrinogen III by either one of two substantially different pathways. In contrast to eukaryotes and most bacteria which employ the so-called "classical" heme biosynthesis pathway, the archaea use an alternative route. In this pathway, heme is formed from uroporphyrinogen III via the intermediates precorrin-2, sirohydrochlorin, siroheme, 12,18-didecarboxysiroheme, and iron-coproporphyrin III. In this study the heme biosynthesis proteins $\mathrm{AhbAB}, \mathrm{AhbC}$, and AhbD from Methanosarcina barkeri were functionally characterized. Using an in vivo enzyme activity assay it was shown that AhbA and AhbB (Mbar_A1459 and Mbar_A1460) together catalyze the conversion of siroheme into 12,18didecarboxysiroheme. The two proteins form a heterodimeric complex which might be subject to feedback regulation by the pathway end-product heme. Further, AhbC (Mbar_A1793) was shown to catalyze the formation of iron-coproporphyrin III in vivo. Finally, recombinant AhbD (Mbar_A1458) was produced in E. coli and purified indicating that this protein most likely contains two [4Fe-4S] clusters. Using an in vitro enzyme activity assay it was demonstrated that AhbD catalyzes the conversion of ironcoproporphyrin III into heme.
\end{abstract}

\section{Introduction}

Heme serves as an essential prosthetic group in many enzymes involved in fundamental biological processes in almost all organisms [1]. In eukaryotes and most bacteria, the biosynthesis of heme proceeds via a conserved, well characterized "classical" pathway [2]. In contrast, heme is formed via an alternative route in the archaea and some bacteria such as the sulfate-reducing Desulfovibrio species [3-9]. In both the classical and the alternative pathway, 5-aminolevulinic acid (ALA) serves as the common precursor for heme formation which is converted into the biosynthetic intermediate uroporphyrinogen III (UROGEN) in three consecutive enzymatic steps. In the classical pathway UROGEN is then converted into heme via the intermediates coproporphyrinogen III, protoporphyrinogen IX, and protoporphyrin IX [2].

In contrast, in the course of the alternative heme biosynthesis route UROGEN is methylated to yield precorrin-2 which is then further transformed into heme via the intermediates sirohydrochlorin, siroheme (SH), 12,18didecarboxysiroheme (DDSH), and iron-coproporphyrin III (Fe-COPRO III) (Figure 1(a)) [6]. Whereas it was known for almost twenty years that the first step of the alternative route is the $S$-adenosyl-L-methionine (SAM) dependent methylation of UROGEN to precorrin-2 [7-9], the remaining steps of the alternative heme biosynthesis pathway were elucidated only recently [6]. The bioinformatic analysis of completely sequenced archaeal genomes revealed the presence of potential heme biosynthesis gene clusters consisting of the "early" hem genes required for the formation of UROGEN and several nir-like genes which encode proteins that are homologous to the enzymes involved in heme $d_{1}$ biosynthesis in denitrifying bacteria (Figure 1(b)) [3]. Similar genes were also identified in the genomes of sulfate-reducing bacteria such as Desulfovibrio vulgaris Hildenborough or Desulfovibrio desulfuricans $[6,10]$. Since most archaea and sulfate-reducing bacteria do not possess a cytochrome $c d_{1}$ nitrite reductase and, thus, do not synthesize heme $d_{1}$, 


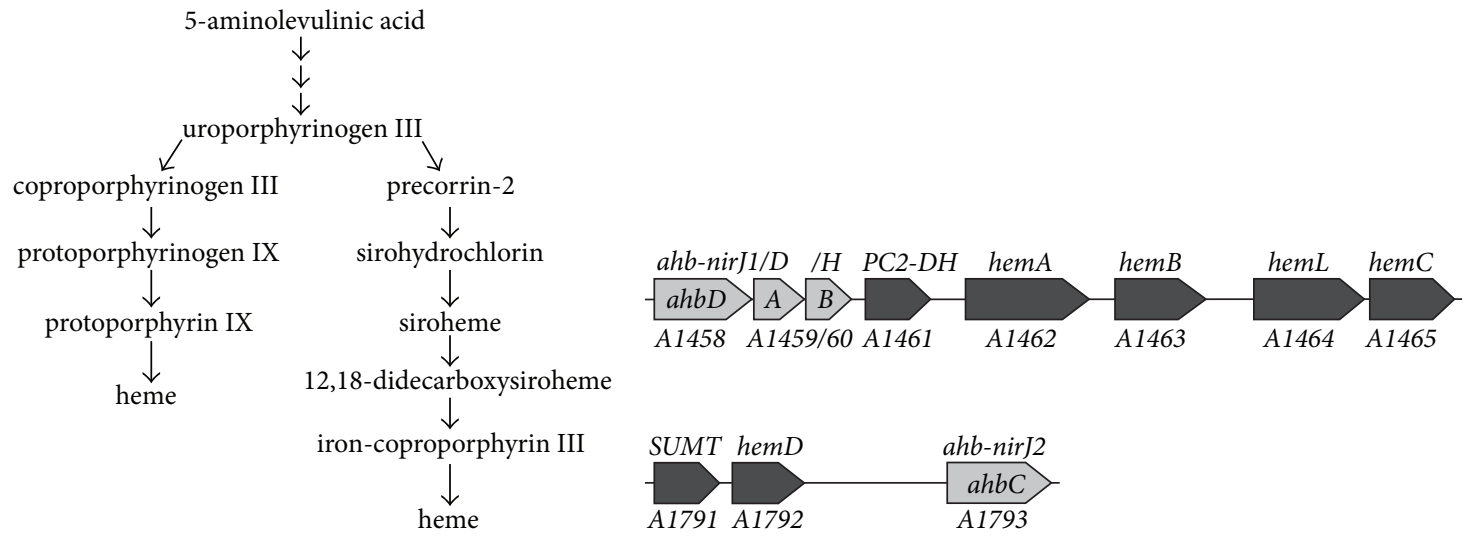

(a)

(b)

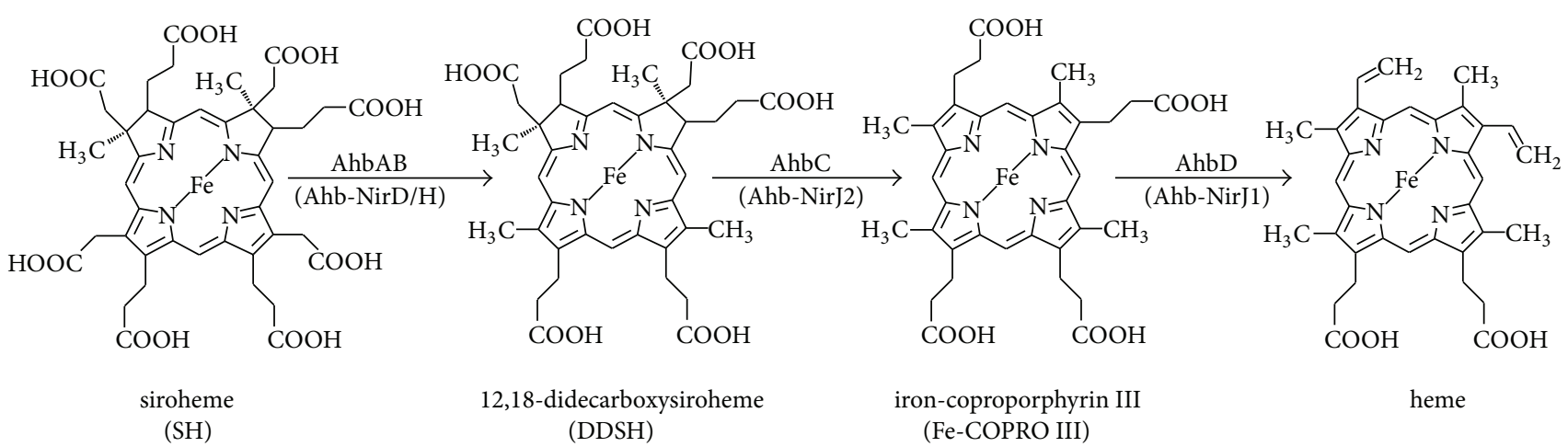

(c)

Figure 1: The alternative heme biosynthesis pathway in Methanosarcina barkeri. (a) Comparison of the classical heme biosynthesis pathway (left hand side) with the alternative pathway (right hand side). In both pathways heme is derived from the common precursor uroporphyrinogen III. In the alternative pathway heme is generated via precorrin-2 requiring a total of six consecutive enzymatic steps. In the classical pathway uroporphyrinogen III is converted into heme via coproporphyrinogen III in four reaction steps. (b) Heme biosynthesis gene clusters in M. barkeri. Genes encoding enzymes which catalyze the early steps during heme formation are shown in black. Genes which were proposed to be important for the last three steps of the alternative heme biosynthesis pathway are shown in grey [3]. The gene numbers for M. barkeri Fusaro (Mbar_) are given below the arrows, the original gene designations [3] are given above the arrows, and the newly suggested names for the genes required for the last three steps are indicated in the grey arrows [6]. (c) The last three steps of the alternative heme biosynthesis pathway. First, the two acetate side chains at positions C-12 and C-18 of siroheme are decarboxylated to methyl groups by Ahb AB resulting in 12,18-didecarboxysiroheme. AhbC removes the acetate side chains at positions C-2 and C-7 to form iron-coproporphyrin III which is finally converted into heme by AhbD through the oxidative decarboxylation of the propionate side chains at positions C-3 and C-8 to the corresponding vinyl groups. The newly suggested enzyme names are given above the arrows [6], and the original enzyme designations are given below the arrows in parentheses [3].

it was speculated that the nir-like genes identified in the genomes of these organisms might be involved in heme biosynthesis. Subsequently, it was shown in vitro that the corresponding recombinant Nir-like proteins from $D$. vulgaris Hildenborough and $D$. desulfuricans were indeed able to catalyze the stepwise conversion of siroheme into heme, that is, the last steps of the alternative heme biosynthesis pathway (Figure 1(c)). According to their newly identified function during the alternative heme biosynthesis, these proteins were given the prefix Ahb [6].

It was shown that $\mathrm{AhbA}$ and $\mathrm{AhbB}$ together catalyzed the decarboxylation of the acetate side chains on rings $\mathrm{C}$ and D of SH to yield DDSH. The same reaction also occurs during heme $d_{1}$ biosynthesis in denitrifying bacteria where it is catalyzed by the homologous proteins NirD, NirL, NirG, and NirH [6]. Next, AhbC was found to catalyze the removal of the acetate side chains on rings $\mathrm{A}$ and $\mathrm{B}$ of DDSH to give Fe-COPRO III. AhbC is homologous to NirJ involved in heme $d_{1}$ biosynthesis. Finally, AhbD was shown to convert Fe-COPRO III into heme by catalyzing the oxidative decarboxylation of the two propionate side chains on rings $A$ and $\mathrm{B}$ to the corresponding vinyl groups [6]. AhbD is also homologous to the heme $d_{1}$ biosynthesis protein NirJ, however, to a lower degree than AhbC. As mentioned above, the enzymatic activities of the Ahb proteins were shown mainly for the recombinant enzymes from the sulfate-reducing bacteria D. vulgaris Hildenborough and D. desulfuricans.

As previously reported and based on bioinformatic analysis, the archaea also possess homologues of these Nir-like alternative heme biosynthesis proteins which were named Ahb-Nir at the time [3]. In this nomenclature, Ahb-NirD corresponds to AhbA, Ahb-NirH to AhbB, Ahb-NirJ2 to 
AhbC, and Ahb-NirJ1 to AhbD (Figure 1(b)). In order to avoid further confusion, we will adopt here the four letter nomenclature (AhbA, AhbB, AhbC, and AhbD) also for the archaeal Ahb-Nir proteins.

Although an equivalent functionality can be inferred for the Ahb proteins from both groups of organisms, that is, sulfate-reducing bacteria and archaea, based on amino acid sequence similarities, these predictions still require experimental proof. Especially, the catalytic functions of AhbC and AhbD should be verified experimentally before the respective enzyme names are assigned, since both proteins share similarity with NirJ and are also quite similar to each other. Therefore, in this study we investigated the catalytic functions of the Ahb proteins from the methanogenic archaeon Methanosarcina barkeri and established their roles for the novel heme biosynthesis pathway in this organism.

\section{Materials and Methods}

2.1. Chemicals. All chemicals and reagents were obtained from Sigma-Aldrich (Taufkirchen, Germany), Carl Roth (Karlsruhe, Germany), Gerbu (Heidelberg, Germany), Merck (Darmstadt, Germany). DNA polymerases, restriction enzymes, and PCR requisites were purchased from New England Biolabs (Frankfurt a.M., Germany). Oligonucleotide primers and plasmid-miniprep kits were purchased from Metabion (Martinsried, Germany). PCR purification and gel extraction kits were obtained from Qiagen (Hilden, Germany). Ni-NTA agarose was purchased from MachereyNagel (Düren, Germany). Porphyrins were purchased from Frontier Scientific (Newark, USA). The four E. coli codonoptimized genes Mbar_A1459,_A1460,_A1458, and _A1793 from $M$. barkeri were synthesized by Life Technologies GmbH (Darmstadt, Germany).

2.2. Construction of Plasmids. For the construction of plasmid pETDuetnirDLGHJEN containing the genes nirD, nirL, nirG, nirH, nirJ, nirE, and nirN from Pseudomonas aeruginosa the DNA fragment containing all seven genes was amplified by PCR with the primers NirDLGHJEN_NdeI_fw (G GAG CGA CAT ATG GAC GAC CTC TCC) and NirDLGHJEN_KpnI_bw (GAC GGT ACC TCA GTG CGA GGT TCC) using plasmid pHAE2 [11] as the template. The amplified DNA fragment was digested with the restriction enzymes NdeI and $K p n I$ (underlined) and ligated into the correspondingly digested vector pETDuet-1 (Novagen, Darmstadt, Germany) to generate pETDuetnirDLGHJEN. For the construction of plasmid pETDuetahbAB the synthetic, codon-optimized gene Mbar_A1460 (encoding AhbB) was amplified by PCR using the primers $15 \mathrm{NirH}$ Mba_fw (C GTA CAT ATG GAT AAA ACC GAT GTG AAA) and 16NirH_Mba_rev (C GTT CTC GAG TTA CAG ACG AAC ACC G). The amplified DNA fragment was digested with the restriction enzymes NdeI and XhoI (underlined) and ligated into correspondingly digested vector pETDuet-1 yielding plasmid pETDuetahbB. The synthetic, codon-optimized gene Mbar_A1459 (encoding AhbA) was amplified by PCR using the primers $13 \mathrm{NirD}$ Mba_fw (TG CAG AAT TCG ATG
ATC GAT ATT GAC AAC CTG) and 14NirD_Mba_rev (TAA CGC GGC CGC TTA ACG AAT ATC GAA). The amplified DNA fragment was digested with the restriction enzymes EcoRI and NotI and ligated into the correspondingly digested plasmid pETDuet $a h b B$ yielding plasmid pETDuetahbAB. The plasmid pET22bahbABCD containing the codon-optimized genes Mbar_A1459, A1460, A1458, and A1793 (encoding AhbABCD) from M. barkeri was constructed by the "link and lock" method as described before [12] using pET22b (Novagen) as the vector system. The plasmid pET22bahbABCD was modified with the QuikChange Site-Directed Mutagenesis Kit (Stratagene) to insert a stop codon (underlined) either in $a h b D$ by using the primers nirJ1_Stop (CTG AAT TGT GTT CAT TGA CGT GGT GCA AGC ACC AG) and nirJ1_Stop_antisense (CTG GT GCT TGC ACC ACG TCA ATG AAC ACA ATT CAG) to generate pET22bahbA $\overline{B C D}_{t 78 a}$ (producing AhbABC) or in $a h b C$ to generate $\mathrm{pET} 22 \mathrm{~b} a h b A B C_{a 76 t} D$ (producing AhbABD) by using the primers nirJ2_Stop (GGT CGT GAT AGC AAA TAA CTG CCG AGC CAT CTG) and nirJ2_Stop_antisense (CAG ATG GCT CGG CAG TTA TTT GCT ATC ACG ACC) for blocking the expression of the respective gene. For the construction of plasmid pETDuet $a h b D$ the codon-optimized gene Mbar_Al458 (encoding AhbD) was PCR amplified using the primers NirJ1_Duet $M f e I \_$fw (C AAT TGG ATG ATT GCC ATG ACC AAT G) and NirJ1_pGEX_XhoI_bw (G CTC GAG TTA TTT TTT ACC CGG AC) containing

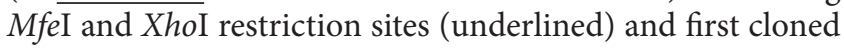
into the pJET1.2/blunt cloning vector (Thermo Scientific) according to the manufacturer's instructions. Mbar_A1458 was then cut from this plasmid with $M f e I$ and $X h o I$ endonucleases and the resulting DNA fragment was ligated into the correspondingly digested vector pETDuet-1 (Novagen) generating pETDuetahbD. Plasmid pBCM-CysG6 encoding the recombinant siroheme synthase CysG from Salmonella typhimurium was kindly provided by Dr. Robert Schnell (Karolinska Institute, Stockholm, Sweden) [13].

\subsection{Bacterial Strains and Growth Conditions. E. coli DH10B} was used as the host for cloning. For production of recombinant proteins the E. coli strain BL21(DE3) was used. For recombinant protein production the E. coli strains carrying the corresponding vectors were grown at $37^{\circ} \mathrm{C}$ in LB-medium (aerobic growth conditions) or LB-medium containing $20 \mathrm{mM} \mathrm{NaNO}_{3}$ (anaerobic growth conditions) supplemented with appropriate antibiotics. Protein production was induced by adding $500 \mu \mathrm{M}$ IPTG (isopropyl- $\beta$-Dthiogalactopyranosid) to the cultures as soon as an optical density at $578 \mathrm{~nm}$ of 0.5 for aerobically and 0.2 for anaerobically grown cultures was reached. Cultures of E. coli cells containing plasmid $\mathrm{pBCM}-\mathrm{Cys}$ G6 were induced for protein production with $0.01 \%(\mathrm{w} / \mathrm{v})$ arabinose. After induction the cells were further cultivated at $25^{\circ} \mathrm{C}$ overnight before harvesting by centrifugation and storing the cell pellet at $-20^{\circ} \mathrm{C}$.

2.4. In Vivo Enzyme Activity Assay. In vivo activity assays were performed by cultivating E. coli BL21(DE3) 
cells containing either only pBCM-CysG6 (production of Salmonella typhimurium CysG) or pBCM-CysG6 in combination with pETDuetnirDLGHJEN (production of $P$. aeruginosa NirDLGH), pETDuetahbAB (production of M. barkeri AhbAB), pET22bahbABCD (production of $M$. barkeri AhbABCD), pET22bahbABCD ${ }_{t 78 a}$ (production of $M$. barkeri AhbABC), or pET22bahbABC ${ }_{a 76 t} D$ (production of $M$. barkeri AhbABD), respectively. The cells were grown anaerobically in $120 \mathrm{~mL}$ plasma bottles and induced for protein production as described above. After overnight cultivation the cells were harvested and either directly used for HPLC sample preparation or stored at $-20^{\circ} \mathrm{C}$.

2.5. Purification of Enzymes. Recombinant AhbAB from M. barkeri was produced aerobically in E. coli BL21(DE3) containing the plasmid pETDuetahbAB and the protein complex was purified by IMAC (immobilized metal ion affinity chromatography). The cell pellet was resuspended in buffer A (50 mM Tris/HCl, pH 7.5, $150 \mathrm{mM} \mathrm{NaCl}, 10 \%$ (v/v) glycerol) and the cells were disrupted using a French Press system (1000 psi). The soluble protein fraction was obtained by ultracentrifugation $\left(45 \mathrm{~min}, 175000 \times \mathrm{g}, 4^{\circ} \mathrm{C}\right)$. The supernatant was loaded on a Ni-NTA column and washed with 10 column volumes (CV) of buffer $\mathrm{A}$ and $2 \mathrm{CV}$ of buffer A containing $50 \mathrm{mM}$ imidazole before eluting the bound proteins with $7 \mathrm{CV}$ of buffer A containing $300 \mathrm{mM}$ imidazole. The protein content of the elution fractions was analyzed by SDS-polyacrylamide gel electrophoresis and the $\mathrm{AhbAB}$ containing fractions were pooled. The final buffer exchange against buffer A was performed with a NAP-25 Sephadex column (Illustra NAP-25, GE Healthcare). The purified $A$ hbAB was stored at $-20^{\circ} \mathrm{C}$.

Recombinant AhbD from M. barkeri was produced in aerobically growing E. coli BL21(DE3) containing the plasmid pETDuetahbD. After cell harvest all procedures done for the purification of AhbD were performed under anaerobic conditions in an anaerobic chamber (Coy Laboratories, Grass Lake, MI, USA). For the resuspension of the cell pellet buffer B (50 mM Tris/HCl, pH 7.5, $250 \mathrm{mM} \mathrm{NaCl}, 0.3 \%$ Triton X100, 2 mM DTT) was used. The soluble protein fraction was obtained as described above. The supernatant was loaded on a $5 \mathrm{~mL}$ Blue Sepharose column (HiTrap Blue HP, GE Healthcare) equilibrated with $50 \mathrm{mM}$ Tris/HCl, pH 7.5, containing $5 \mathrm{mM}$ DTT and after sample application the column was washed thoroughly with this buffer. The bound proteins were eluted using a linear gradient from $0 \mathrm{M} \mathrm{NaCl}$ to $1 \mathrm{M}$ $\mathrm{NaCl}$ in $50 \mathrm{mM}$ Tris/ $\mathrm{HCl}, \mathrm{pH} 7.5$, containing $5 \mathrm{mM}$ DTT. The AhbD containing fractions (elution at about $500 \mathrm{mM} \mathrm{NaCl}$ ) were pooled and the buffer was exchanged against $50 \mathrm{mM}$ Tris/ $\mathrm{HCl}$, pH 8.0, containing $5 \mathrm{mM}$ DTT. Then, the protein solution was loaded on an anion exchange column (Mono Q 5/50 GL, GE Healthcare) equilibrated with $50 \mathrm{mM}$ Tris/ $\mathrm{HCl}$, pH 8.0, containing $5 \mathrm{mM}$ DTT and the column was washed with the same buffer. A linear gradient from $0 \mathrm{M} \mathrm{NaCl}$ to $0.5 \mathrm{M} \mathrm{NaCl}$ in $50 \mathrm{mM}$ Tris/ $\mathrm{HCl}, \mathrm{pH} 8.0$, containing $5 \mathrm{mM}$ DTT was used for the elution of the bound proteins. The AhbD containing fractions were pooled and concentrated to $5.6 \mathrm{mg} / \mathrm{mL}$. The purified AhbD was stored at $4^{\circ} \mathrm{C}$.
2.6. Dialysis of $A h b A B .100 \mu \mathrm{L}$ of purified $\mathrm{AhbAB}$ at a concentration of $7.8 \mathrm{mg} / \mathrm{mL}$ were dialyzed at $4^{\circ} \mathrm{C}$ overnight against $100 \mathrm{~mL}$ of buffer A using a Slide-A-Lyzer dialysis cassette (10k MWCO, Thermo Scientific, Waltham, MA USA). Then, the used buffer A was exchanged against $100 \mathrm{~mL}$ of fresh buffer $\mathrm{A}$ and the dialysis was continued at $4^{\circ} \mathrm{C}$ for another three hours.

2.7. Determination of Protein Concentration. For the determination of protein concentrations the Bradford Reagent (Sigma-Aldrich) was used according to the manufacturer's instructions with BSA as the protein standard.

2.8. In Vitro Iron-Sulfur Cluster Reconstitution. The in vitro reconstitution of iron-sulfur clusters was performed as previously described [14]. After reconstitution the excess of iron and sulfide was removed by centrifugation and subsequent passage of the protein solution through a NAP-25 column (GE Healthcare) which was used according to the manufacturer's instructions.

2.9. Determination of Iron and Sulfide Contents. The iron content of purified AhbD was determined according to [15] after denaturation of the protein with $1 \mathrm{M}$ perchloric acid and using bathophenanthroline as the chelating reagent. The sulfide content was determined as previously described [16].

2.10. Molecular Mass Determination. The native molecular mass of purified proteins was estimated by gel permeation chromatography as previously described [3].

2.11. In Vitro Enzyme Activity Assay for AhbAB. The assay was performed under anaerobic conditions in a glove box (Coy Laboratories). The substrate siroheme was produced in vivo by the production of recombinant CysG in E. coli as described above. Then, a crude cell free extract was prepared under anaerobic conditions from the siroheme containing E. coli cells which was used directly as the substrate solution for the activity assay. The assay mixtures contained in a total volume of $250 \mu \mathrm{L}$ of assay buffer $(50 \mathrm{mM}$ Tris/ $\mathrm{HCl}$, $\mathrm{pH} 7.5,300 \mathrm{mM} \mathrm{NaCl}, 5 \%$ (v/v) glycerol) a final concentration of $20 \mu \mathrm{M}$ purified $\mathrm{AhbAB}$ which was incubated prior to substrate addition with $0 \mu \mathrm{M}, 5 \mu \mathrm{M}$, or $20 \mu \mathrm{M}$ hemin. Then, $75 \mu \mathrm{L}$ of the siroheme containing cell free extract was added to start the reaction. For the control reaction AhbAB and hemin were omitted from the mixture. The reactions were incubated at $37^{\circ} \mathrm{C}$ for $19 \mathrm{~h}$. Then, the accumulated tetrapyrroles were extracted from the assay mixtures and analyzed by HPLC as described below.

2.12. In Vitro Enzyme Activity Assay for AhbD. The assay was performed under anaerobic conditions in a glove box (Coy Laboratories). A stock solution of $500 \mu \mathrm{M}$ ironcoproporphyrin III (Fe-COPRO III) was generated according to Chim et al. [17]. The enzyme activity assay mixture contained $20 \mu \mathrm{M}$ Fe-COPRO III, $500 \mu \mathrm{M}$ S-adenosylL-methionine (SAM), $1 \mathrm{mM}$ sodium dithionite (DT), and $5 \mu \mathrm{M}$ purified, reconstituted AhbD in buffer $\mathrm{B}$. The reaction 
mixtures were incubated for $6 \mathrm{~h}$ and $15 \mathrm{~h}$ at $17^{\circ} \mathrm{C}$. To stop the enzymatic reaction $5 \%(\mathrm{v} / \mathrm{v})$ of concentrated $\mathrm{HCl}$ was added to the mixture which was stored at $-20^{\circ} \mathrm{C}$ until further use.

2.13. Tetrapyrrole Extraction and Preparation of HPLC Samples. For the extraction of the potential heme bound to purified $\mathrm{AhbAB}$ the protein solution was mixed $1: 1(\mathrm{v} / \mathrm{v})$ with solution 1 (50 mM Tris/ $\mathrm{HCl}, \mathrm{pH} 8.0$, and $2 \%$ Tween 80 ) and $5 \%(\mathrm{v} / \mathrm{v})$ of concentrated $\mathrm{HCl}$ was added to denature the proteins. After shaking the mixture on a Vortex-Genie 2 mixer (Scientific Industries Inc., Bohemia, NY, USA) for two minutes the sample was centrifuged $(10 \mathrm{~min}, 16100 \times \mathrm{g})$. Then, an acetone/ $\mathrm{HCl}$ mixture $(39: 1(\mathrm{v} / \mathrm{v}))$ was added $1: 1(\mathrm{v} / \mathrm{v})$ to the supernatant followed by another centrifugation step. The resulting supernatant containing the extracted tetrapyrroles was analyzed by HPLC.

For the preparation of HPLC samples of the in vivo enzyme activity assays the cell pellets were resuspended $1: 4(\mathrm{w} / \mathrm{v})$ in solution 1 . The cells were disrupted with glass beads in a cell disruptor (10 min, $3000 \mathrm{rpm})$ and centrifuged $(10 \mathrm{~min}, 16100 \times \mathrm{g})$. Addition of $600 \mu \mathrm{L}$ acetone/HCl $(39: 1$ $(\mathrm{v} / \mathrm{v}))$ to $200 \mu \mathrm{L}$ of the supernatant and vortexing for 10 minutes was used to extract the tetrapyrroles and precipitate the proteins. The samples were centrifuged $(10 \mathrm{~min}$, $16100 \times \mathrm{g})$ and the supernatant was concentrated in a speed vac (Eppendorf, Hamburg, Germany) to a final volume of $200 \mu \mathrm{L}$ before adding $5 \%(\mathrm{v} / \mathrm{v})$ of concentrated $\mathrm{HCl}$ and centrifuging $(10 \mathrm{~min}, 16100 \times \mathrm{g})$. The obtained supernatant was used for HPLC analysis.

For the preparation of HPLC samples of the in vitro enzyme activity assays the assay mixture was mixed $1: 1(\mathrm{v} / \mathrm{v})$ with acetone/ $\mathrm{HCl}(39: 1(\mathrm{v} / \mathrm{v}))$ followed by vortexing and centrifugation $(10 \mathrm{~min}, 16100 \times \mathrm{g}) .5 \%(\mathrm{v} / \mathrm{v})$ of concentrated $\mathrm{HCl}$ was added to the supernatant and centrifuged again to remove residual protein before injection into the HPLC system.

\subsection{Preparation of HPLC Standards. Hemin or} Fe-COPRO III was first dissolved in $150 \mu \mathrm{L}$ of acetone $/ \mathrm{HCl}$ $(39: 1(\mathrm{v} / \mathrm{v}))$ and then $75 \mu \mathrm{L}$ of solution 1 was added. The obtained tetrapyrrole solutions were centrifuged $(10 \mathrm{~min}$, $16100 \times \mathrm{g}$ ) and the supernatant was used for HPLC analysis.

2.15. High Performance Liquid Chromatography of Tetrapyrroles. Tetrapyrrole extracts were analyzed using a JASCO HPLC 2000 series system (Jasco, Gross-Umstadt, Germany). The tetrapyrroles were detected by photometric diode array analysis at $200-650 \mathrm{~nm}$ and by fluorescence measurements using an excitation wavelength of $409 \mathrm{~nm}$ and an emission wavelength of $630 \mathrm{~nm}$.

The chromatographic separation of samples $(30 \mu \mathrm{L}$ injection volume) containing heme and Fe-COPRO III was performed on an Equisil BDS C18 column (Dr. Maisch HPLC $\mathrm{GmbH}$, Ammerbuch-Entringen, Germany) with $5 \mu \mathrm{m}$ particle size and $250 \mathrm{~mm} \times 4.6 \mathrm{~mm}$ column dimensions at $25^{\circ} \mathrm{C}$. The tetrapyrroles were eluted at a flow rate of $0.5 \mathrm{~mL} / \mathrm{min}$ using a gradient system based on previously published methods [18]. Solvent A consisted of $1 \mathrm{M}$ ammonium acetate ( $\mathrm{pH}$ 5.2) (analytical grade, Sigma-Aldrich), solvent $\mathrm{B}$ of methanol (HPLC grade, Sigma-Aldrich), and solvent C of acetonitrile (HPLC grade, Sigma-Aldrich). At the time of sample injection the mobile phase consisted of $60 \%$ solvent $A$, $30 \%$ solvent $\mathrm{B}$, and $10 \%$ solvent $\mathrm{C}$. Within $30 \mathrm{~min}$ the content of solvent B was increased to $75 \%$ with concomitant decrease of solvent A to $15 \%$ while solvent $\mathrm{C}$ was held constant at $10 \%$. Then, the content of solvent B was increased to $90 \%$ within 5 min while solvent $\mathrm{C}$ was held constant at $10 \%$. These conditions (90\% B and 10\% C) were held for 15 min before returning to the initial conditions.

The separation of samples $(20 \mu \mathrm{L}$ injection volume) containing siroheme and 12,18-didecarboxysiroheme was performed on a ReproSil-Pur C18 AQ column (Dr. Maisch HPLC GmbH) with $5 \mu \mathrm{m}$ particle size and $150 \mathrm{~mm} \times 2 \mathrm{~mm}$ column dimensions at $25^{\circ} \mathrm{C}$ and a flow rate of $0.2 \mathrm{~mL} / \mathrm{min}$. For the elution of the tetrapyrroles a gradient system was used with solvent A consisting of $0.01 \%(\mathrm{v} / \mathrm{v})$ formic acid in water (analytical grade, Merck) and solvent B consisting of acetonitrile (HPLC grade, Sigma-Aldrich). The initial conditions of the mobile phase consisted of $95 \%$ solvent A and $5 \%$ solvent B, which was increased to $20 \%$ within 6 min. Then, the content of solvent B was increased to $30 \%$ within $19 \mathrm{~min}$ and finally increased to $100 \%$ within $5 \mathrm{~min}$ and held for $10 \mathrm{~min}$ before returning to the initial conditions.

2.16. HPLC-MS Analysis of Siroheme and 12,18-Didecarboxysiroheme. The HPLC separation of the tetrapyrroles was performed as described above. The masses of the eluting tetrapyrroles were measured by ESI-MS on an LTQ XL linear ion trap mass spectrometer (Thermo Fisher Scientific) in the positive ion mode.

2.17. UV-Visible Absorption Spectroscopy. UV-visible absorption spectra of purified proteins were recorded using either a V-600 or a V-650 spectrophotometer (Jasco, Gross-Umstadt, Germany).

2.18. N-Terminal Sequencing. The N-terminal sequence of the purified protein was determined by Edman degradation.

\section{Results and Discussion}

3.1. AhbA and AhbB from Methanosarcina barkeri Catalyze the Decarboxylation of Siroheme to 12,18-Didecarboxysiroheme. During the alternative heme biosynthesis route the acetate side chains on rings $\mathrm{C}$ and $\mathrm{D}$ of siroheme are decarboxylated to the corresponding methyl groups (Figure 1(c)). This reaction is catalyzed by enzymes (AhbA and AhbB) that are homologous to the heme $d_{1}$ biosynthesis enzymes NirD, NirL, NirG, and NirH which catalyze the same reaction during heme $d_{1}$ formation in denitrifying bacteria such as Paracoccus pantotrophus or Pseudomonas aeruginosa [6]. In $M$. barkeri the potential AhbA and AhbB proteins are encoded by the genes Mbar_A1459 and Mbar_A1460, respectively (Figure $1(\mathrm{~b})$ ). Whereas in $M$. barkeri and other methanogenic archaea AhbA and AhbB are encoded by two distinct genes, these two genes are fused to one single 

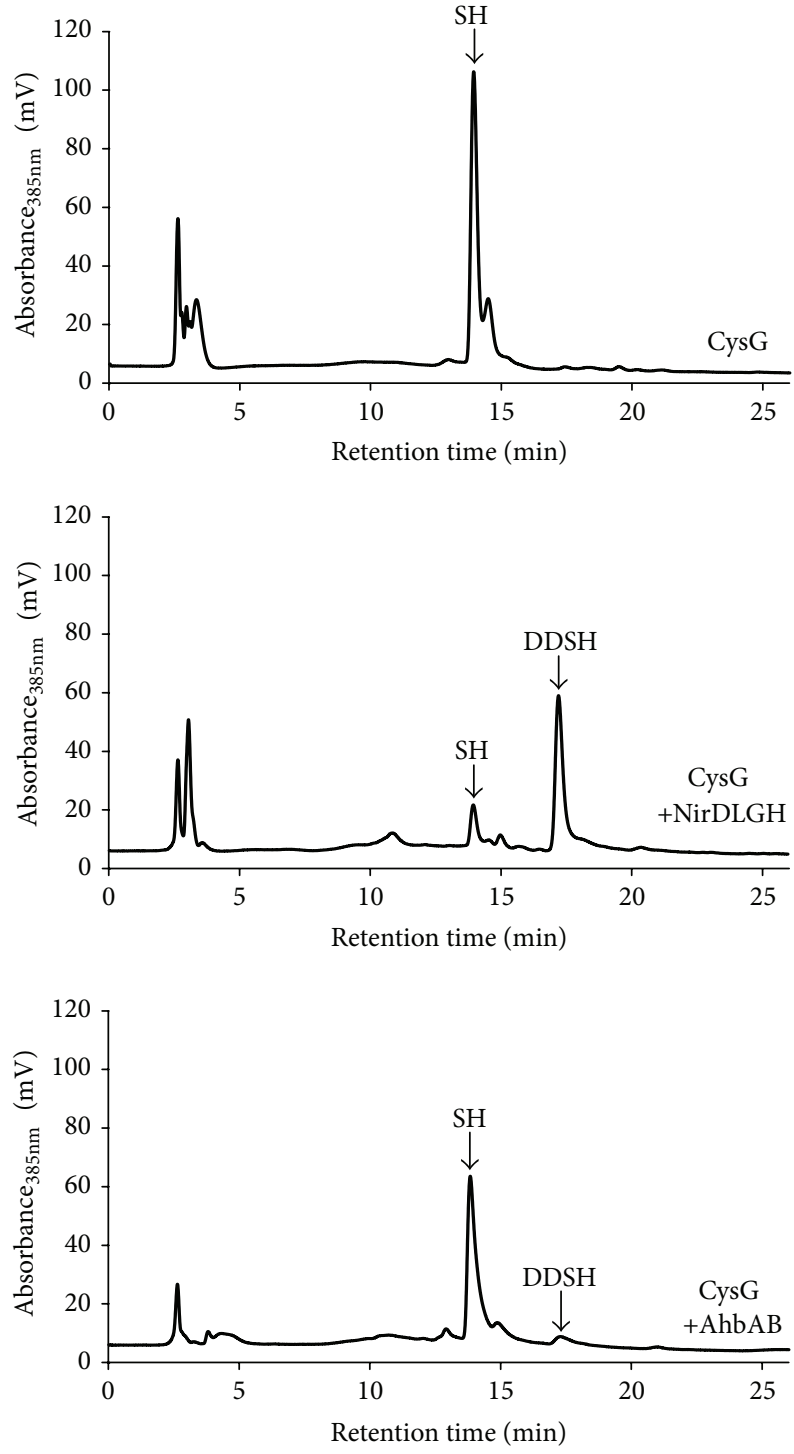

(a)
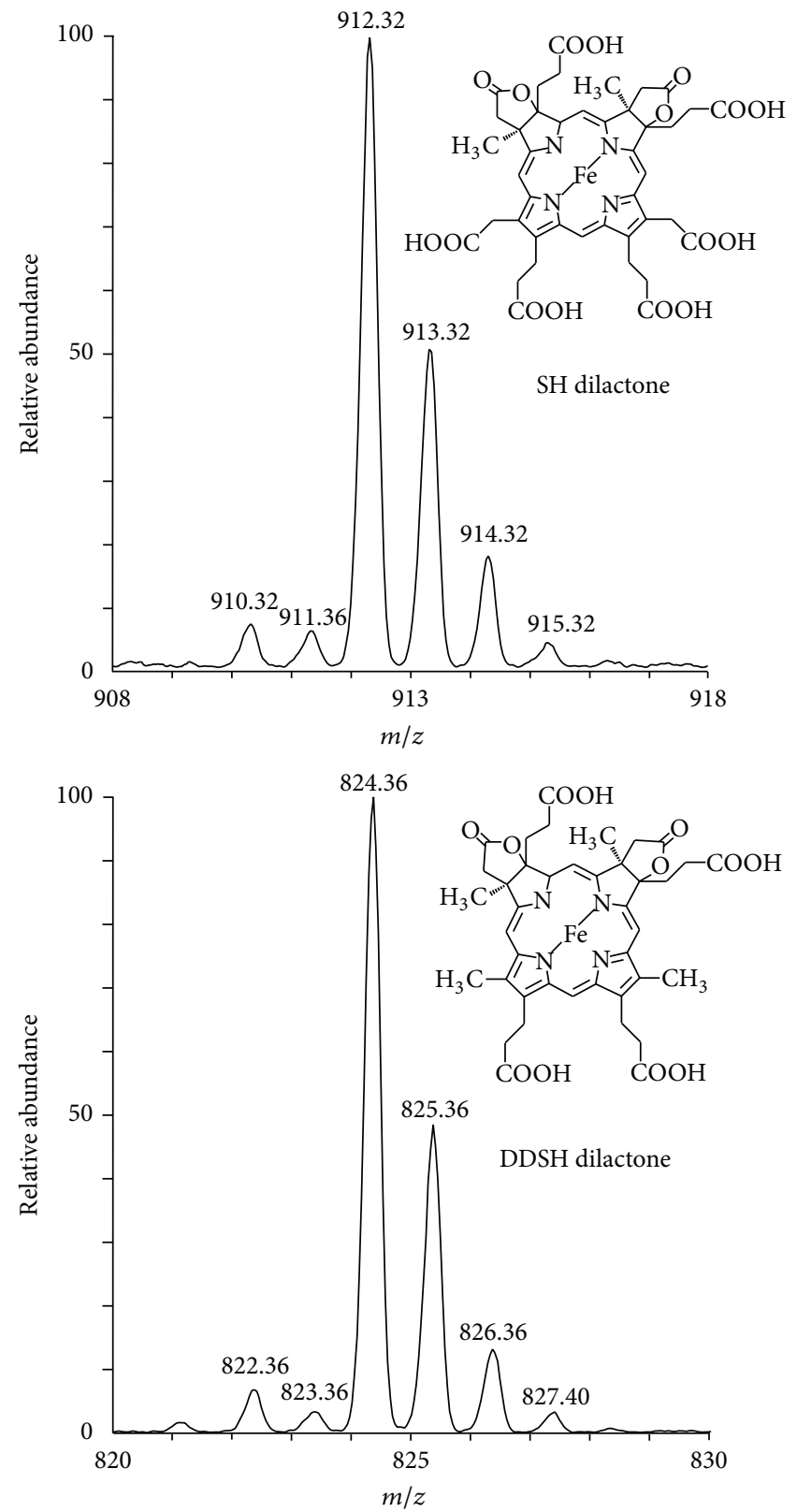

(b)

Figure 2: AhbA and AhbB from M. barkeri act as siroheme decarboxylase in vivo. (a) HPLC analysis of the tetrapyrroles accumulated in different E. coli strains. The HPLC analysis of cell free extracts from E. coli cells producing recombinant CysG (upper panel) shows the accumulation of siroheme (SH). In the presence of CysG and recombinant NirDLGH from Pseudomonas aeruginosa 12,18didecarboxysiroheme (DDSH) is formed (middle panel). In the presence of CysG and recombinant AhbAB from M. barkeri DDSH is formed (lower panel). (b) Isotopic mass spectra of SH (upper panel) and DDSH (lower panel) after HPLC separation. Both SH and DDSH eluted from the column in their dilactone form probably due to oxidation during tetrapyrrole extraction.

gene in all other heme-synthesizing archaea [3]. Therefore, it is reasonable to assume that $\mathrm{AhbA}$ and $\mathrm{AhbB}$ together catalyze the decarboxylation of siroheme in $M$. barkeri as observed for the homologous proteins from Desulfovibrio species [6]. Thus, in the following we will name the siroheme decarboxylase $\mathrm{AhbAB}$. In order to experimentally verify the predicted function of AhbAB from M. barkeri as a siroheme decarboxylase, we developed an in vivo enzyme activity assay. In this assay, siroheme, the substrate of $A h b A B$, was produced in E. coli by the recombinant siroheme synthase CysG from Salmonella typhimurium encoded on plasmid pBCM-CysG6 [13]. After overnight CysG production, the siroheme ( $\mathrm{SH}$ ) content of the E. coli cells was analyzed by tetrapyrrole extraction and HPLC analysis as described in Materials and Methods and shown in Figure 2(a). Next, we coproduced recombinant CysG together with recombinant 


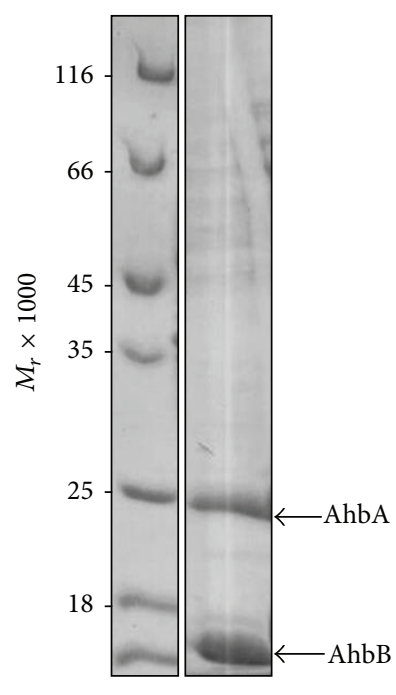

(a)

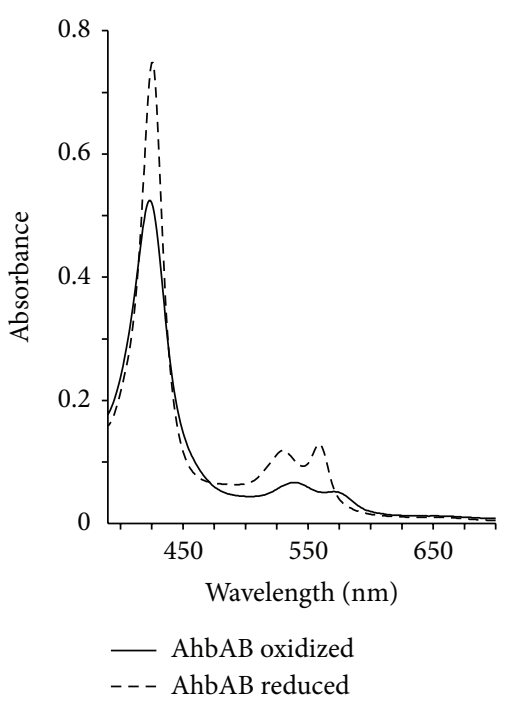

(b)
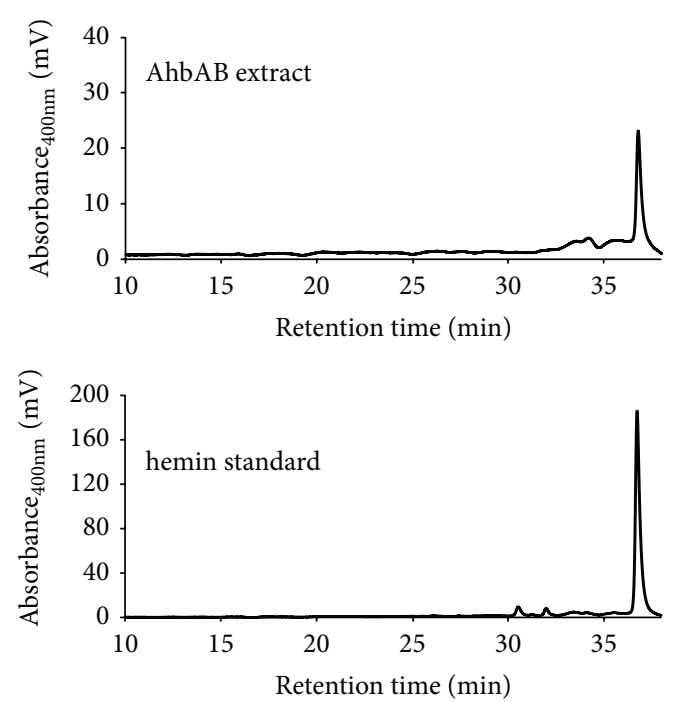

(c)

FIGURE 3: AhbAB from M. barkeri is a heme binding heterodimeric complex. (a) SDS-PAGE analysis of the purified AhbAB complex after copurification of $\mathrm{His}_{6}$-tagged AhbA with nontagged AhbB on Ni-NTA agarose. The $M_{r}$ values of the marker proteins are indicated. (b) UVvisible absorption spectra of purified $\mathrm{AhbAB}$ in the oxidized form (as isolated, solid line) and the dithionite-reduced state (dashed line). (c) HPLC analysis of extracted tetrapyrroles of AhbAB. The comparison of the retention time of the extracted tetrapyrrole (upper panel) with a hemin standard (lower panel) suggests the presence of heme in purified AhbAB.

AhbA and AhbB from M. barkeri in the same E. coli host and analyzed the accumulated tetrapyrroles after overnight protein production as before. Additionally, the same experiment was performed with recombinant NirD, NirL, NirG, and NirH from $P$. aeruginosa, constituting the potential siroheme decarboxylase for heme $d_{1}$ formation in this organism, which were all coproduced with CysG as a positive control.

As shown in Figure 2(a), the HPLC analysis of the tetrapyrroles extracted from E. coli cells producing only CysG revealed the presence of one major compound at a retention time of 13.9 min which was identified as SH by HPLC-MS analysis (Figure 2(b)). The detected mass of 912.36 for the $[\mathrm{M}+\mathrm{H}]^{+}$ion corresponded to $\mathrm{SH}$ in its dilactone form. The formation of lactone derivatives of isobacteriochlorins was observed previously [19-21] and probably occurred during the tetrapyrrole extraction under aerobic conditions. Nevertheless, this result showed that $\mathrm{SH}$, the potential substrate for AhbAB from M. barkeri, accumulated in CysG producing E. coli cells. When recombinant NirD, NirL, NirG, and NirH from $P$. aeruginosa were coproduced together with CysG in the same E. coli host, only residual amounts of SH were detected by HPLC analysis at a retention time of 13.9 min and a new major compound emerged at a retention time of about $17.2 \mathrm{~min}$. The mass of this compound $\left(824.36\right.$ for the $[\mathrm{M}+\mathrm{H}]^{+}$ ion) corresponded to 12,18-didecarboxysiroheme (DDSH) in its dilactone form (Figure 2(b)). Thus, this result not only showed that our in vivo activity assay was suitable for the detection of SH decarboxylase activity, but also demonstrated for the first time that NirD, NirL, NirG, and NirH from $P$. aeruginosa indeed represent the $\mathrm{SH}$ decarboxylase for heme $d_{1}$ formation in this denitrifying bacterium. Finally, DDSH was also formed in vivo when AhbA and AhbB from M. barkeri were co-produced together with $\mathrm{CysG}$ as judged by HPLC analysis of the extracted tetrapyrroles (Figure 2(a)). This result clearly established that the $M$. barkeri genes Mbar_A1459 and Mbar_A1460 encode the SH decarboxylase AhbAB.

3.2. AhbA and $A h b B$ from Methanosarcina barkeri form a Heterodimeric, Heme-Binding Complex. In M. barkeri and other methanogenic archaea, the $\mathrm{SH}$ decarboxylase $\mathrm{AhbAB}$ is composed of two protein subunits encoded by two distinct genes. In contrast, in all other heme-synthesizing archaea these two genes are fused to one single gene encoding the predicted $\mathrm{SH}$ decarboxylase in these organisms [3]. Therefore, we hypothesized that AhbA and AhbB from $M$. barkeri might form a mixed complex with each other in vivo which represents the physiological relevant form of the enzyme. In order to test this hypothesis, we coproduced recombinant AhbA carrying an $\mathrm{N}$-terminal $\mathrm{His}_{6}$-tag together with nontagged AhbB in the same E. coli host. Then, $\mathrm{His}_{6}$ AhbA was purified by affinity chromatography on Ni-NTA agarose and the protein content of the final elution fraction was analyzed by SDS-PAGE. As shown in Figure 3(a), the nontagged $\mathrm{AhbB}$ was copurified together with $\mathrm{His}_{6}$-AhbA during this experiment strongly suggesting the formation of a mixed $A$ hbAB complex in vivo. Further, the purified complex was analyzed by gel permeation chromatography which revealed the presence of a heterodimer (data not shown). Based on these novel results, we propose that the $\mathrm{SH}$ decarboxylase from $M$. barkeri is a heterodimeric enzyme consisting of the two subunits AhbA and AhbB.

Interestingly, the purified $\mathrm{AhbAB}$ complex was bright orange in color. The UV-visible absorption spectra of the purified protein in the as isolated and the dithionite-reduced form suggested the presence of a bound heme cofactor 
with absorption maxima at 423, 539, and $571 \mathrm{~nm}$ for the as isolated form and absorption maxima at 426, 530, and $559 \mathrm{~nm}$ in the dithionite-reduced form (Figure 3(b)). In order to characterize the bound chromophore in more detail, the purified protein was denatured by the addition of hydrochloric acid and the potential heme cofactor was extracted by acidified acetone. Subsequently, the extracted chromophore was analyzed by HPLC and was identified as heme $b$ based on its retention time (Figure 3(c)) and UVvisible absorption spectrum (data not shown). Although the bound heme was removed from the AhbAB complex under denaturing conditions, we were unable to separate the protein-chromophore complex by dialysis. The ratio of heme to $\mathrm{AhbAB}$ was estimated by peak integration after HPLC analysis and was determined to be about $0.03 \mathrm{~mol}$ heme per mol AhbAB. In summary, these results clearly showed for the first time that AhbA and AhbB from M. barkeri form a heterodimeric AhbAB complex which partially contains a noncovalently, but tightly bound heme $b$.

The presence of heme $b$ in the purified AhbAB complex was completely unexpected. Usually, heme $b$ serves as a redox cofactor in enzymes or as a gas sensor in regulatory proteins. However, there is no need for a redox cofactor in the siroheme decarboxylase AhbAB and the homologous proteins NirDLGH which catalyze the same reaction during the biosynthesis of heme $d_{1}$ do not contain any bound heme $b$ after purification (K. Haufschildt and G. Layer, unpublished results). A potential role of the heme $b$ as a cofactor for the catalytic activity of AhbAB seems unlikely considering that $A$ hbAB catalyzes a reaction during the biosynthesis of the cofactor itself. Such a situation would raise the "chicken and egg" question. Alternatively, there are several different possibilities for the role of the bound heme in AhbAB. First, the presence of heme in the $\mathrm{AhbAB}$ preparation might reflect an end-product inhibition mechanism which controls the catalytic activity of AhbAB. In such a mechanism, the hemefree AhbAB complex would catalyze the decarboxylation of $\mathrm{SH}$ to DDSH in M. barkeri when heme is needed. As soon as the demand for heme is satisfied, the cofactor would bind to the AhbAB complex and might possibly inhibit its catalytic activity. Second, heme binding to AhbAB might control protein stability as observed for glutamyl-tRNA reductase which was reported to be inhibited upon heme binding and also seemed to be more amenable to proteolytic degradation in the heme-bound form [22-24]. The eukaryotic 5aminolevulinic acid synthase (ALAS1) represents another example for a feedback-regulation by heme. In this case, gene expression and protein stability were reported to be dependent on the heme levels in mitochondria $[25,26]$. Therefore, a third mechanism might be that heme-bound AhbAB might somehow influence gene expression of the heme biosynthesis genes. In this context it is interesting to note that the proteins $\mathrm{AhbA}$ and $\mathrm{AhbB}$ are annotated in the databases as transcriptional regulators belonging to the Lrp/AsnC-family.

3.3. Heme Does Not Inhibit the In Vitro Enzyme Activity of Purified $A h b A B$. In order to obtain more insights into the role of the heme bound to $\mathrm{AhbAB}$ we tested the possibility that heme might inhibit the catalytic activity of the protein. For this purpose, we tested the AhbAB activity in an in vitro enzyme activity assay in the absence and presence of different amounts of added heme as described in the Materials and Methods section. As shown in Figure 4, DDSH was formed by the action of purified AhbAB independent of the absence or presence of added heme. Even in the presence of equimolar amounts of heme with respect to the enzyme no inhibition of $\mathrm{AhbAB}$ was observed. These results indicate that heme does not inhibit the catalytic activity of AhbAB. Nevertheless, AhbAB might be subject to feedback-regulation by heme by one of the other possible mechanisms described above.

3.4. AhbC from Methanosarcina barkeri Catalyzes the Formation of Iron-Coproporphyrin III. During the alternative heme biosynthesis in archaea and sulfate-reducing bacteria the AhbC protein catalyzes the removal of the acetate side chains on rings $\mathrm{A}$ and $\mathrm{B}$ of DDSH yielding Fe-COPRO III. AhbC is a predicted Radical SAM enzyme homologous to the heme $d_{1}$ biosynthesis enzyme NirJ $[3,6]$. The heme biosynthesis gene clusters of $M$. barkeri (Figure 1(b)) contain two genes encoding two distinct NirJ-like proteins (previously named Ahb-NirJ1 and Ahb-NirJ2 [3]). The gene Mbar_A1793 encodes a protein which shares $38.8 \%$ amino acid sequence identity with $P$. aeruginosa NirJ and, thus, most likely represents AhbC. The second NirJ-like protein in $M$. barkeri, which shares $29.5 \%$ sequence identity with $P$. aeruginosa NirJ, is encoded by the gene Mbar_A1458 and probably represents AhbD, the terminal enzyme of the alternative heme biosynthesis pathway. In order to experimentally verify these functional predictions, we chose the same in vivo assay strategy as before for AhbAB. Thus, we coproduced recombinant CysG from S. typhimurium and AhbAB from M. barkeri together with either AhbC (Mbar_A1793) or AhbD (Mbar_A1458) or both AhbC and AhbD from M. barkeri in the same E. coli host. After overnight protein production the accumulated tetrapyrroles were extracted from the $E$. coli cell free extracts and analyzed by HPLC.

As shown in Figure 5, Fe-COPRO III (retention time $19.6 \mathrm{~min}$ ) was produced in E. coli cells in the presence of recombinant CysG, AhbAB, and either both AhbC and $\mathrm{AhbD}$ or AhbC alone. In contrast, no Fe-COPRO III was produced in the presence of CysG, AhbAB, and AhbD when AhbC was missing in the in vivo assay. These results clearly demonstrated that the gene Mbar_A1793 indeed encodes the enzyme AhbC which is responsible for the conversion of DDSH into Fe-COPRO III during the alternative heme biosynthesis in M. barkeri.

\subsection{AhbD from Methanosarcina barkeri Is an Iron-Sulfur} Cluster Containing Radical SAM Heme Synthase. So far, we were able to assign the respective enzymatic functions to the M. barkeri proteins Mbar_A1459, Mbar_A1460, and Mbar_A1793 by the use of our in vivo activity assay. However, in order to establish the enzymatic function of Mbar_A1458 as a heme synthase that converts Fe-COPRO III into heme, the in vivo strategy in E. coli was not suitable, since E. coli produces heme by itself via the classical pathway. Therefore, 

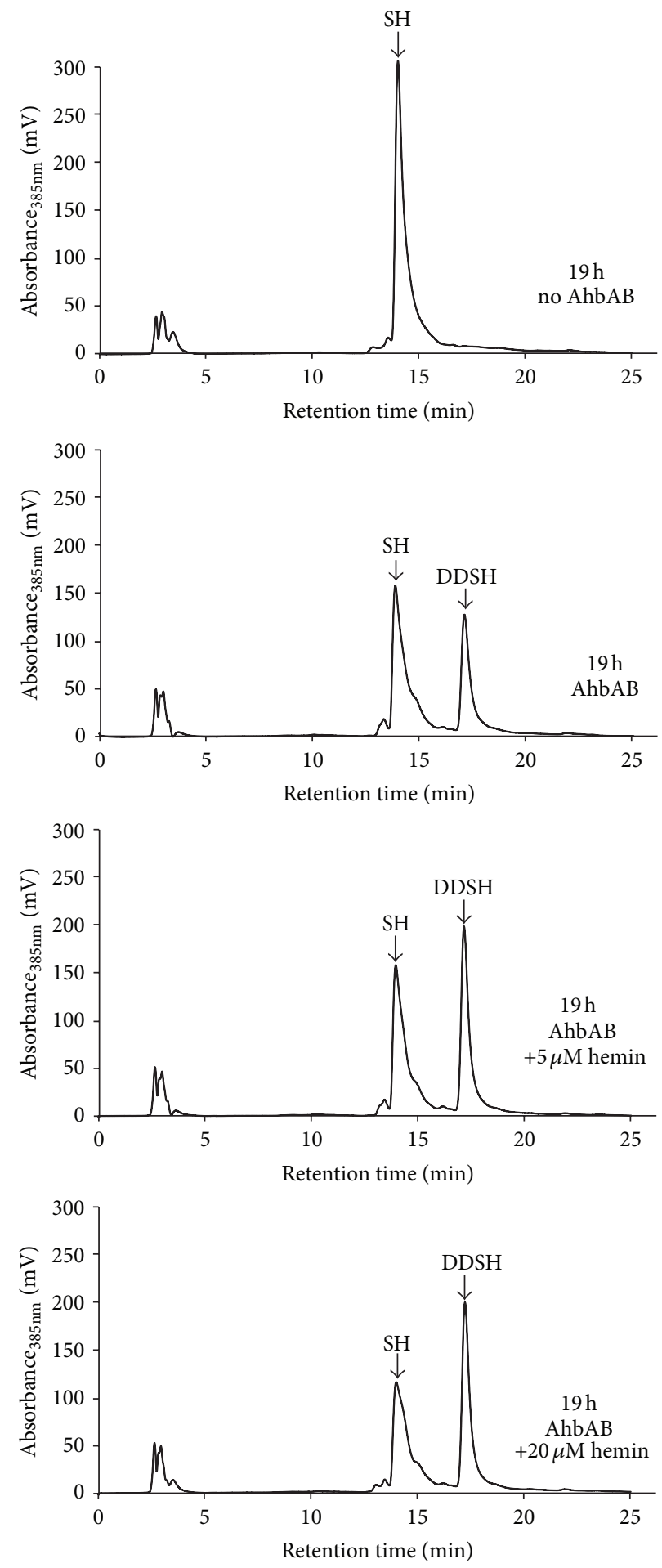

FIgURE 4: AhbAB is not inhibited by heme in vitro. The AhbAB enzyme activity assay was performed as described in Materials and Methods. In the absence of purified AhbAB no 12,18-didecarboxysiroheme (DDSH) is formed from siroheme (SH) (upper panel). In the presence of $20 \mu \mathrm{M}$ AhbAB, DDSH is formed independent of the amounts of added heme (other panels) suggesting that heme does not inhibit the in vitro activity of AhbAB.

the potential AhbD from M. barkeri (Mbar_A1458) was produced as a recombinant protein in E. coli and purified, in order to establish an in vitro enzyme activity assay. The recombinant AhbD did not carry any additional tag and was purified by affinity chromatography on a HiTrap Blue
HP column (GE Healthcare) and subsequent anion exchange chromatography on a Mono Q 5/50 GL column (GE Healthcare) as described in the Materials and Methods section. Using this purification strategy about $0.9 \mathrm{mg}$ of $\mathrm{AhbD}$ was obtained from $1 \mathrm{~L}$ of bacterial culture. After purification, the 

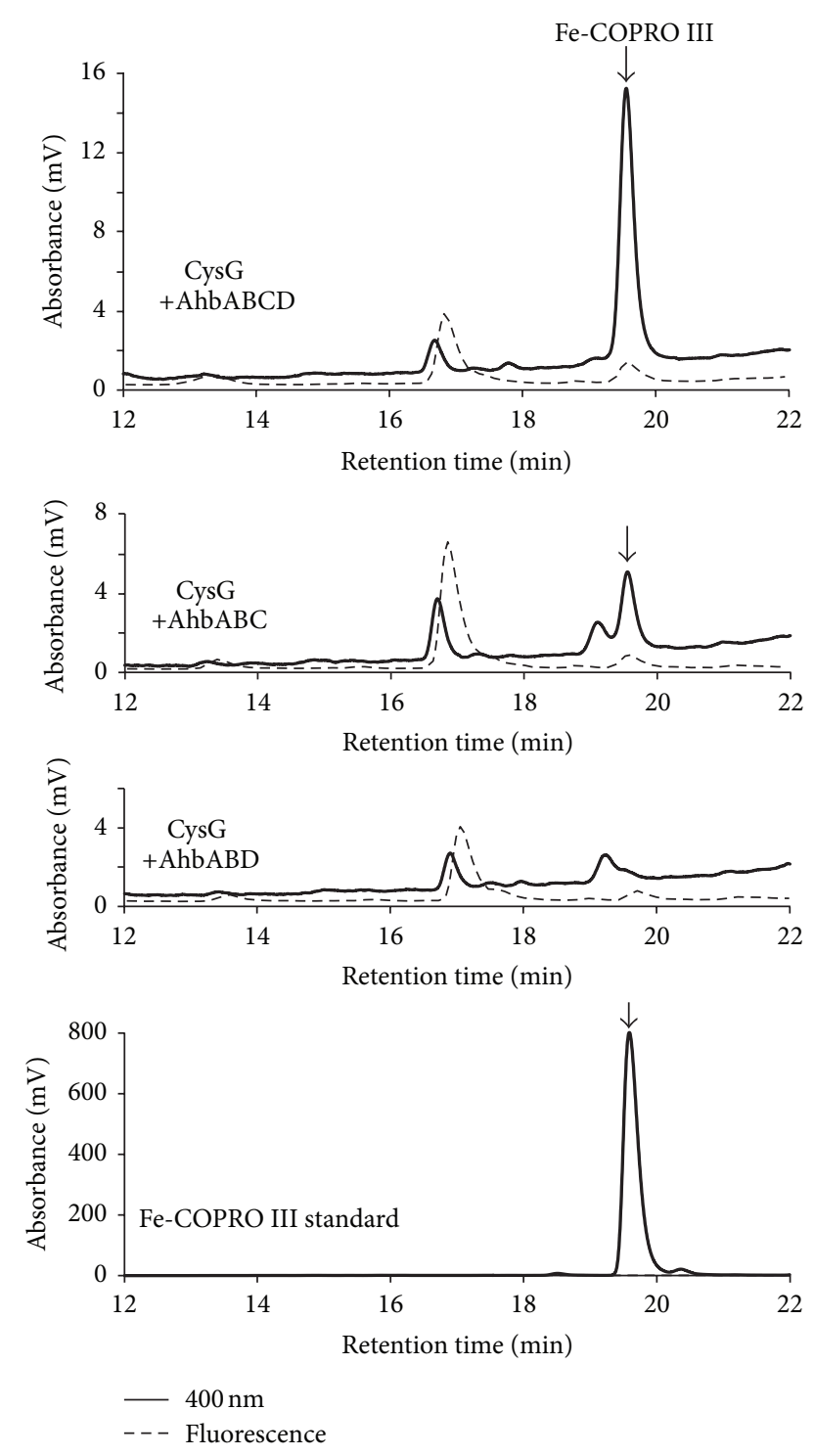

FIGURE 5: AhbC from M. barkeri generates iron-coproporphyrin III in vivo. The HPLC analysis of cell free extracts from E. coli cells producing recombinant CysG and recombinant $\mathrm{AhbAB}, \mathrm{AhbC}$, and AhbD from M. barkeri (upper panel) showed the accumulation of iron-coproporphyrin III (Fe-COPRO III). In E. coli cells producing recombinant CysG together with recombinant $\mathrm{AhbAB}$ and $\mathrm{AhbC}$ the formation of Fe-COPRO III was also observed (second panel). In contrast, the coproduction of CysG with AhbAB and AhbD did not result in the formation of Fe-COPRO III (third panel). The chromatographic behavior of the Fe-COPRO III standard is shown in the lower panel.

protein exhibited a slightly brownish color and the UV-visible absorption spectrum (not shown) of purified AhbD displayed a broad absorption feature at around $410 \mathrm{~nm}$ indicating the presence of an iron-sulfur cluster. As mentioned above, AhbD belongs to the family of Radical SAM enzymes and, therefore, the presence of a $[4 \mathrm{Fe}-4 \mathrm{~S}]$ cluster which is coordinated by the three cysteine residues of the characteristic amino acid sequence motif $\mathrm{CX}_{3} \mathrm{CX}_{2} \mathrm{C}$ was expected [27]. Moreover, the amino acid sequence of $\mathrm{AhbD}$ contains a second conserved cysteine-rich region at the C-terminus exhibiting the sequence motif $\mathrm{CX}_{2} \mathrm{CX}_{5} \mathrm{CX}_{20} \mathrm{C}$. Therefore, $\mathrm{AhbD}$ might harbor a second iron-sulfur cluster in addition to the one that is coordinated by the cysteines of the Radical SAM cysteine motif $\left(\mathrm{CX}_{3} \mathrm{CX}_{2} \mathrm{C}\right)$ which is found at the N-terminus of AhbD. In order to obtain more insight into the iron-sulfur content of $\mathrm{AhbD}$, we determined the iron content of the anaerobically purified protein. We observed that purified AhbD contained only $2.2 \mathrm{~mol}$ iron per mol AhbD which was less than expected for a protein containing at least one [ $4 \mathrm{Fe}-4 \mathrm{~S}]$ cluster. However, this observation could be explained either by partial loss of the iron-sulfur cluster(s) during purification or by incomplete iron-sulfur cluster incorporation in vivo during recombinant protein production. Therefore, the purified AhbD was subjected to in vitro iron-sulfur cluster reconstitution as described in the Materials and Methods section. After cluster reconstitution and removal of excess iron and sulfide the protein exhibited an intense brown color and the UV-visible absorption spectrum indicated the presence of $[4 \mathrm{Fe}-4 \mathrm{~S}]$ clusters (Figure 6(a)). Subsequently, the iron and sulfide contents of the protein were determined. We observed that reconstituted AhbD contained $8.5 \mathrm{~mol}$ iron per mol AhbD and $5.1 \mathrm{~mol}$ sulfide per mol AhbD. These results indicate that AhbD most likely contains two [4Fe$4 \mathrm{~S}$ ] clusters and therefore belongs to the subfamily of Radical SAM enzymes that contain more than one iron-sulfur cluster [28].

In order to determine whether the purified, reconstituted $\mathrm{AhbD}$ was able to catalyze the conversion of Fe-COPRO III to heme, an in vitro enzyme activity assay was established. In this assay the purified protein was incubated with the substrate Fe-COPRO III together with the cofactor $S$ adenosyl-L-methionine (SAM) and sodium dithionite (DT) as the reductant for the iron-sulfur cluster of AhbD. After incubation of the mixture at $17^{\circ} \mathrm{C}$ for $0 \mathrm{~h}, 6 \mathrm{~h}$, and $15 \mathrm{~h}$ the reaction was stopped by the addition of hydrochloric acid. The tetrapyrroles present in the reaction mixtures were extracted and subjected to HPLC analysis (Figure 6(b)). At the beginning of the reaction $(0 \mathrm{~h})$ only Fe-COPRO III was present in the mixture (Figure 6(b), first panel). After $6 \mathrm{~h}$ of incubation the amount of Fe-COPRO III had clearly decreased and two new compounds emerged at retention times of about $30.1 \mathrm{~min}$ and $37.5 \mathrm{~min}$ (Figure 6(b), second panel). The compound at $37.5 \mathrm{~min}$ retention time was heme as revealed by comparison with the chromatographic behavior of a hemin standard (see also Figure 3(c)). The compound at about 30.1 min retention time might be a monovinyl reaction intermediate. Finally, after $15 \mathrm{~h}$ the substrate Fe-COPRO III and the potential monovinyl intermediate completely disappeared and only the reaction product heme was detected in the reaction mixture (Figure 6(b), third panel). In contrast, when purified $\mathrm{AhbD}$ was omitted from the reaction mixture, no conversion of Fe-COPRO III to heme was observed after $15 \mathrm{~h}$ (Figure 6(b), fourth panel). The same was true when the "as isolated" enzyme (not reconstituted) was used (data not shown) showing that the full incorporation of the iron-sulfur clusters was required for AhbD activity. These results clearly 


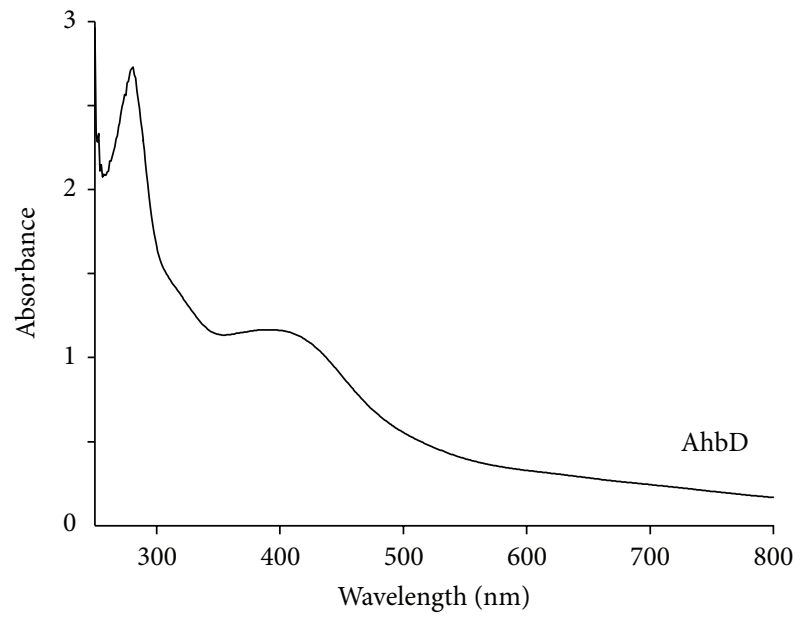

(a)
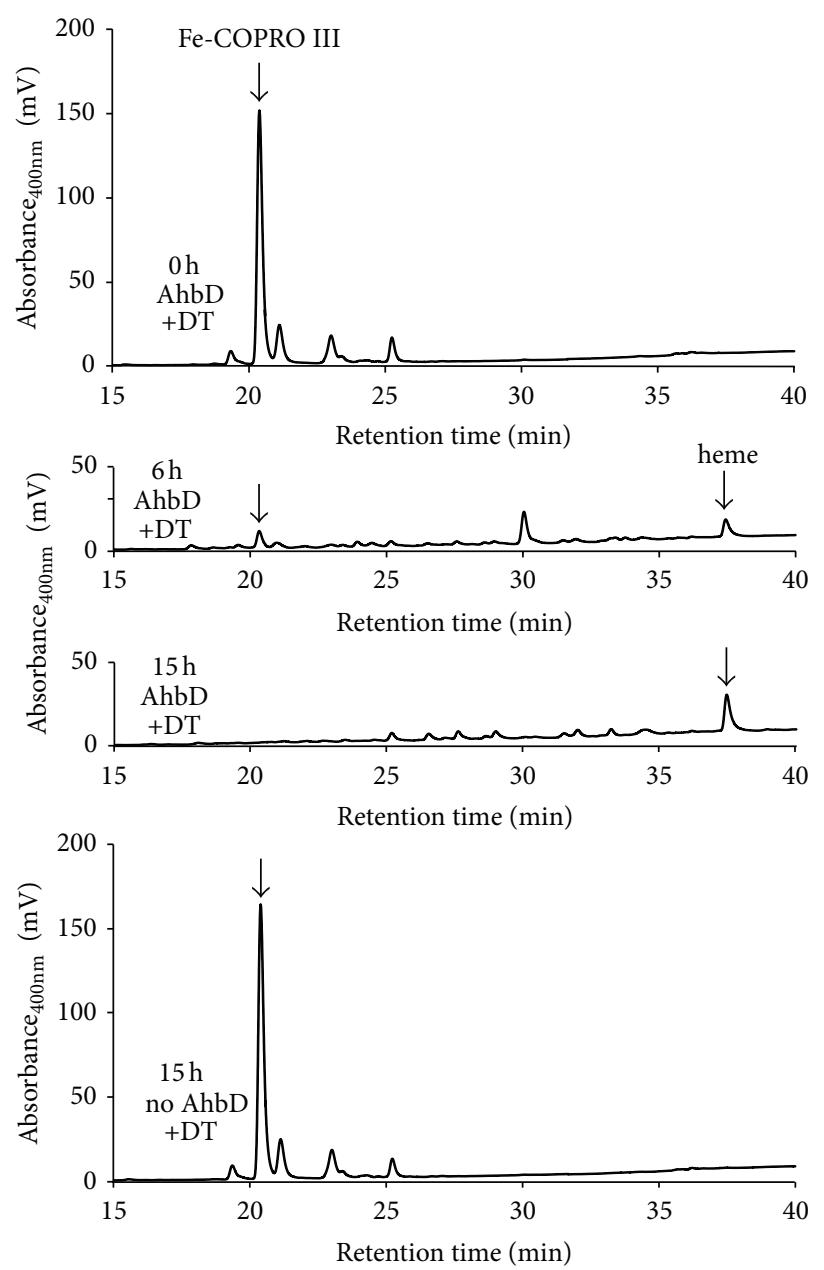

(b)

FIGURE 6: AhbD from M. barkeri acts as heme synthase in vitro. (a) UV-visible absorption spectrum of purified AhbD after in vitro ironsulfur cluster reconstitution. (b) HPLC analysis of the tetrapyrrole content of AhbD enzyme activity assay mixtures. The in vitro activity assay mixture contained reconstituted AhbD $(5 \mu \mathrm{M})$, Fe-COPRO III $(20 \mu \mathrm{M})$, SAM $(500 \mu \mathrm{M})$, and sodium dithionite $(1 \mathrm{mM})$ as reducing agent and was incubated at $17^{\circ} \mathrm{C}$. The tetrapyrrole content of the mixture was analyzed by HPLC after $0 \mathrm{~h}$ (upper panel), $6 \mathrm{~h}$ (second panel), and $15 \mathrm{~h}$ (third panel) of incubation. After $6 \mathrm{~h}$ the formation of heme was detected $(37.5 \mathrm{~min})$ as well as the formation of a potential monovinyl intermediate $(30.1 \mathrm{~min})$. After $15 \mathrm{~h}$ of incubation the substrate Fe-COPRO III was completely consumed as well as the potential reaction intermediate and heme was detected as the sole reaction product. In contrast, no heme formation was observed after $15 \mathrm{~h}$ in a control reaction in which the purified $\mathrm{AhbD}$ was omitted from the assay mixture. 
established the enzymatic function of Mbar_A1458 as AhbD, that is, a heme synthase that converts Fe-COPRO III into heme during the alternative heme biosynthesis pathway in Methanosarcina barkeri.

\section{Conclusion}

In heme-synthesizing archaea heme is formed via an alternative pathway which differs significantly from the long known classical pathway found in most bacteria and eukaryotes. Previously, several archaeal genes were identified which were proposed to be involved in this alternative pathway, however, the function of only two of them was experimentally verified [3]. In this study, the predicted functions of the enzymes catalyzing the last three steps of the alternative heme biosynthesis pathway in $M$. barkeri were verified. Therefore, for $M$. barkeri the two enzymes which consecutively convert uroporphyrinogen III into sirohydrochlorin [3] and the three enzymes which convert siroheme into heme (this study) were biochemically characterized. The only missing enzyme to complete the whole pathway in this organism is the chelatase which incorporates iron into sirohydrochlorin to form siroheme. Several potential chelatases are encoded in the $M$. barkeri genome and future studies will have to show which of them acts as the iron-chelatase during heme formation.

\section{Conflict of Interests}

The authors declare that there is no conflict of interests regarding the publication of this paper.

\section{Acknowledgments}

The authors would like to thank Dr. Robert Schnell (Karolinska Institute Stockholm, Sweden) for the kind gift of plasmid pBCM-CysG6 [13] as well as Professor Dr. Dieter Jahn and Dr. Jürgen Moser (Technische Universität Braunschweig, Germany) for helpful discussions. This work was financially supported by Grants from the Deutsche Forschungsgemeinschaft (LA 2412/2-1) and the Fonds der Chemischen Industrie to G. Layer.

\section{References}

[1] A. R. Battersby, "Tetrapyrroles: the pigments of life," Natural Product Reports, vol. 17, no. 6, pp. 507-526, 2000.

[2] G. Layer, J. Reichelt, D. Jahn, and D. W. Heinz, "Structure and function of enzymes in heme biosynthesis," Protein Science, vol. 19, no. 6, pp. 1137-1161, 2010.

[3] S. Storbeck, S. Rolfes, E. Raux-Deery, M. J. Warren, D. Jahn, and G. Layer, "A novel pathway for the biosynthesis of heme in Archaea: genome-based bioinformatic predictions and experimental evidence," Archaea, vol. 2010, Article ID 175050, 15 pages, 2010.

[4] G. Cavallaro, L. Decaria, and A. Rosato, "Genome-based analysis of heme biosynthesis and uptake in prokaryotic systems," Journal of Proteome Research, vol. 7, no. 11, pp. 4946-4954, 2008.
[5] H. Panek and M. R. O'Brian, "A whole genome view of prokaryotic haem biosynthesis," Microbiology, vol. 148, no. 8, pp. 2273-2282, 2002.

[6] S. Bali, A. D. Lawrence, S. A. Lobo et al., "Molecular hijacking of siroheme for the synthesis of heme and $\mathrm{d}_{1}$ heme," Proceedings of the National Academy of Sciences of the United States of America, vol. 108, no. 45, pp. 18260-18265, 2011.

[7] H. Akutsu, J.-S. Park, and S. Sano, "L-methionine methyl is specifically incorporated into the C-2 and C-7 positions of the porphyrin of cytochrome $c_{3}$ in a strictly anaerobic bacterium, Desulfovibrio vulgaris," Journal of the American Chemical Society, vol. 115, no. 25, pp. 12185-12186, 1993.

[8] B. Buchenau, J. Kahnt, I. U. Heinemann, D. Jahn, and R. K. Thauer, "Heme biosynthesis in Methanosarcina barkeri via a pathway involving two methylation reactions," Journal of Bacteriology, vol. 188, no. 24, pp. 8666-8668, 2006.

[9] T. Ishida, L. Yu, H. Akutsu et al., "A primitive pathway of porphyrin biosynthesis and enzymology in Desulfovibrio vulgaris," Proceedings of the National Academy of Sciences of the United States of America, vol. 95, no. 9, pp. 4853-4858, 1998.

[10] S. A. L. Lobo, A. Brindley, M. J. Warren, and L. M. Saraiva, "Functional characterization of the early steps of tetrapyrrole biosynthesis and modification in Desulfovibrio vulgaris Hildenborough," Biochemical Journal, vol. 420, no. 2, pp. 317-325, 2009.

[11] S. Kawasaki, H. Arai, T. Kodama, and Y. Igarashi, "Gene cluster for dissimilatory nitrite reductase (nir) from Pseudomonas aeruginosa: sequencing and identification of a locus for heme $\mathrm{d}_{1}$ biosynthesis," Journal of Bacteriology, vol. 179, no. 1, pp. 235242, 1997.

[12] H. M. McGoldrick, C. A. Roessner, E. Raux et al., "Identification and characterization of a novel vitamin $\mathrm{B}_{12}$ (cobalamin) biosynthetic enzyme (CobZ) from Rhodobacter capsulatus, containing flavin, heme, and Fe-S cofactors," Journal of Biological Chemistry, vol. 280, no. 2, pp. 1086-1094, 2005.

[13] R. Schnell, T. Sandalova, U. Hellman, Y. Lindqvist, and G. Schneider, "Siroheme- and [Fe4-S4]-dependent NirA from Mycobacterium tuberculosis is a sulfite reductase with a covalent Cys-Tyr bond in the active site," Journal of Biological Chemistry, vol. 280, no. 29, pp. 27319-27328, 2005.

[14] L. Flühe, T. A. Knappe, M. J. Gattner et al., “The radical SAM enzyme AlbA catalyzes thioether bond formation in subtilosin A," Nature Chemical Biology, vol. 8, no. 4, pp. 350-357, 2012.

[15] W. W. Fish, "Rapid colorimetric micromethod for the quantitation of complexed iron in biological samples," Methods in Enzymology, vol. 158, pp. 357-364, 1988.

[16] H. Beinert, "Semi-micro methods for analysis of labile sulfide and of labile sulfide plus sulfane sulfur in unusually stable ironsulfur proteins," Analytical Biochemistry, vol. 131, no. 2, pp. 373378, 1983.

[17] N. Chim, A. Iniguez, T. Q. Nguyen, and C. W. Goulding, "Unusual diheme conformation of the heme-degrading protein from Mycobacterium tuberculosis," Journal of Molecular Biology, vol. 395, no. 3, pp. 595-608, 2010.

[18] M. Danton and C. K. Lim, "Porphyrin profiles in blood, urine and faeces by HPLC/electrospray ionization tandem mass spectrometry," Biomedical Chromatography, vol. 20, no. 6-7, pp. 612-621, 2006.

[19] S. Storbeck, J. Walther, J. Müller et al., “The Pseudomonas aeruginosa nirE gene encodes the S-adenosyl-L-methioninedependent uroporphyrinogen III methyltransferase required for heme $\mathrm{d}_{1}$ biosynthesis," FEBS Journal, vol. 276, no. 20, pp. 5973-5982, 2009. 
[20] A. R. Battersby, K. Jones, E. McDonald, J. A. Robinson, and H. R. Morris, "The structures and chemistrty of isobacteriochlorins from Desulphovibrio gigas," Tetrahedron Letters, vol. 18, no. 25, pp. 2213-2216, 1977.

[21] A. R. Battersby, E. McDonald, H. R. Morris et al., "Biosynthesis of vitamin $\mathrm{B}_{12}$ : structural studies on the corriphryins from Propionibacterium shermanii and the link with sirohydrochlorin," Tetrahedron Letters, vol. 18, no. 25, pp. 2217-2220, 1977.

[22] M. de Armas-Ricard, G. Levicán, A. Katz, J. Moser, D. Jahn, and O. Orellana, "Cellular levels of heme affect the activity of dimeric glutamyl-tRNA reductase," Biochemical and Biophysical Research Communications, vol. 405, no. 1, pp. 134-139, 2011.

[23] A. M. Jones and T. Elliott, "A purified mutant HemA protein from Salmonella enterica serovar Typhimurium lacks bound heme and is defective for heme-mediated regulation in vivo," FEMS Microbiology Letters, vol. 307, no. 1, pp. 41-47, 2010.

[24] A. Srivastava and S. I. Beale, "Glutamyl-tRNA reductase of Chlorobium vibrioforme is a dissociable homodimer that contains one tightly bound heme per subunit," Journal of Bacteriology, vol. 187, no. 13, pp. 4444-4450, 2005.

[25] J. Zheng, Y. Shan, R. W. Lambrecht, S. E. Donohue, and H. L. Bonkovsky, "Differential regulation of human ALAS1 mRNA and protein levels by heme and cobalt protoporphyrin," Molecular and Cellular Biochemistry, vol. 319, no. 1-2, pp. 153161, 2008.

[26] K. Yoshino, H. Munakata, O. Kuge, A. Ito, and T. Ogishima, "Haeme-regulated degradation of $\delta$-aminolevulinate synthase 1 in rat liver mitochondria," Journal of Biochemistry, vol. 142, no. 4, pp. 453-458, 2007.

[27] H. J. Sofia, G. Chen, B. G. Hetzler, J. F. Reyes-Spindola, and N. E. Miller, "Radical SAM, a novel protein superfamily linking unresolved steps in familiar biosynthetic pathways with radical mechanisms: functional characterization using new analysis and information visualization methods," Nucleic Acids Research, vol. 29, no. 5, pp. 1097-1106, 2001.

[28] N. D. Lanz and S. J. Booker, "Identification and function of auxiliary iron-sulfur clusters in radical SAM enzymes," Biochimica et Biophysica Acta, vol. 1824, no. 11, pp. 1196-1212, 2012. 

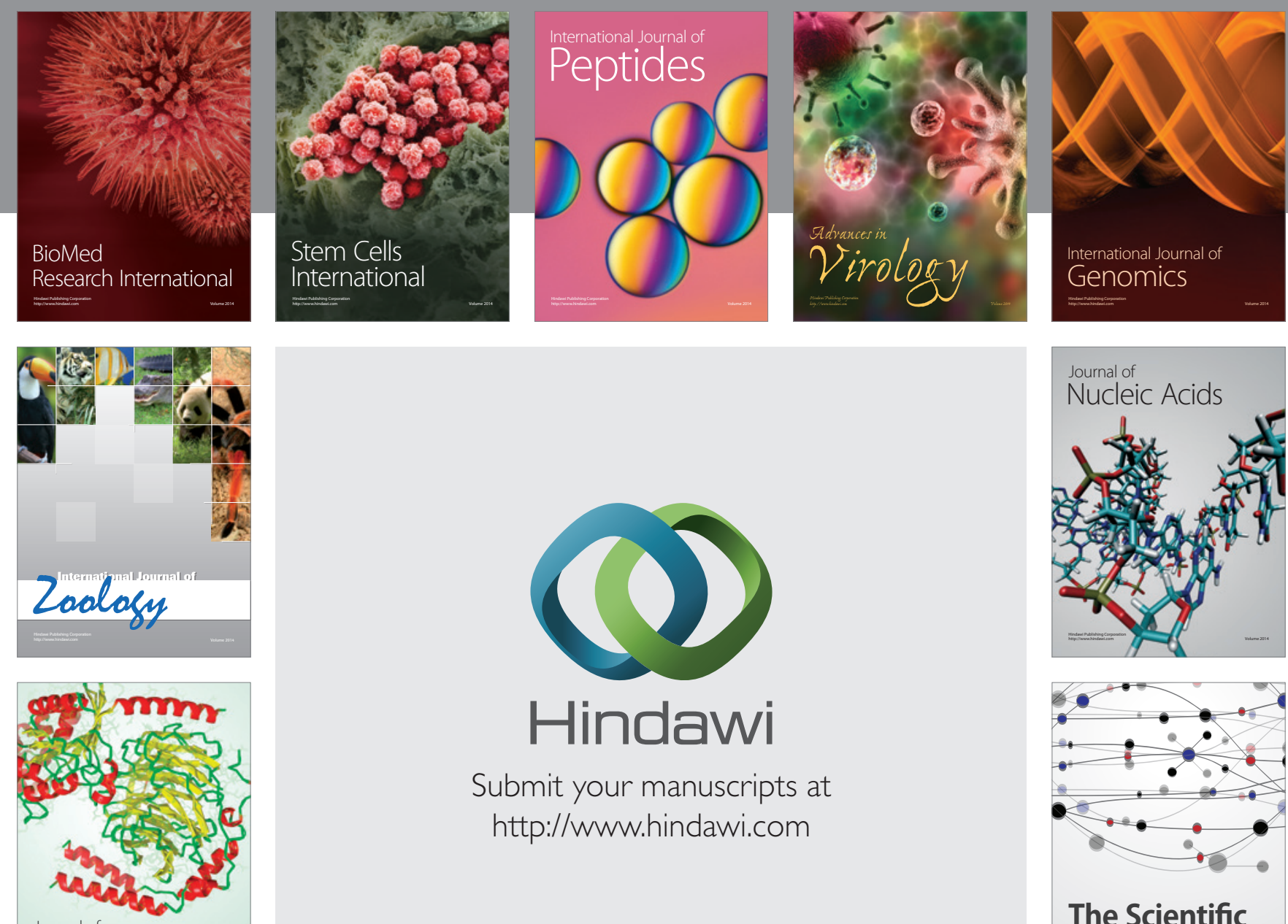

Submit your manuscripts at

http://www.hindawi.com

Journal of
Signal Transduction
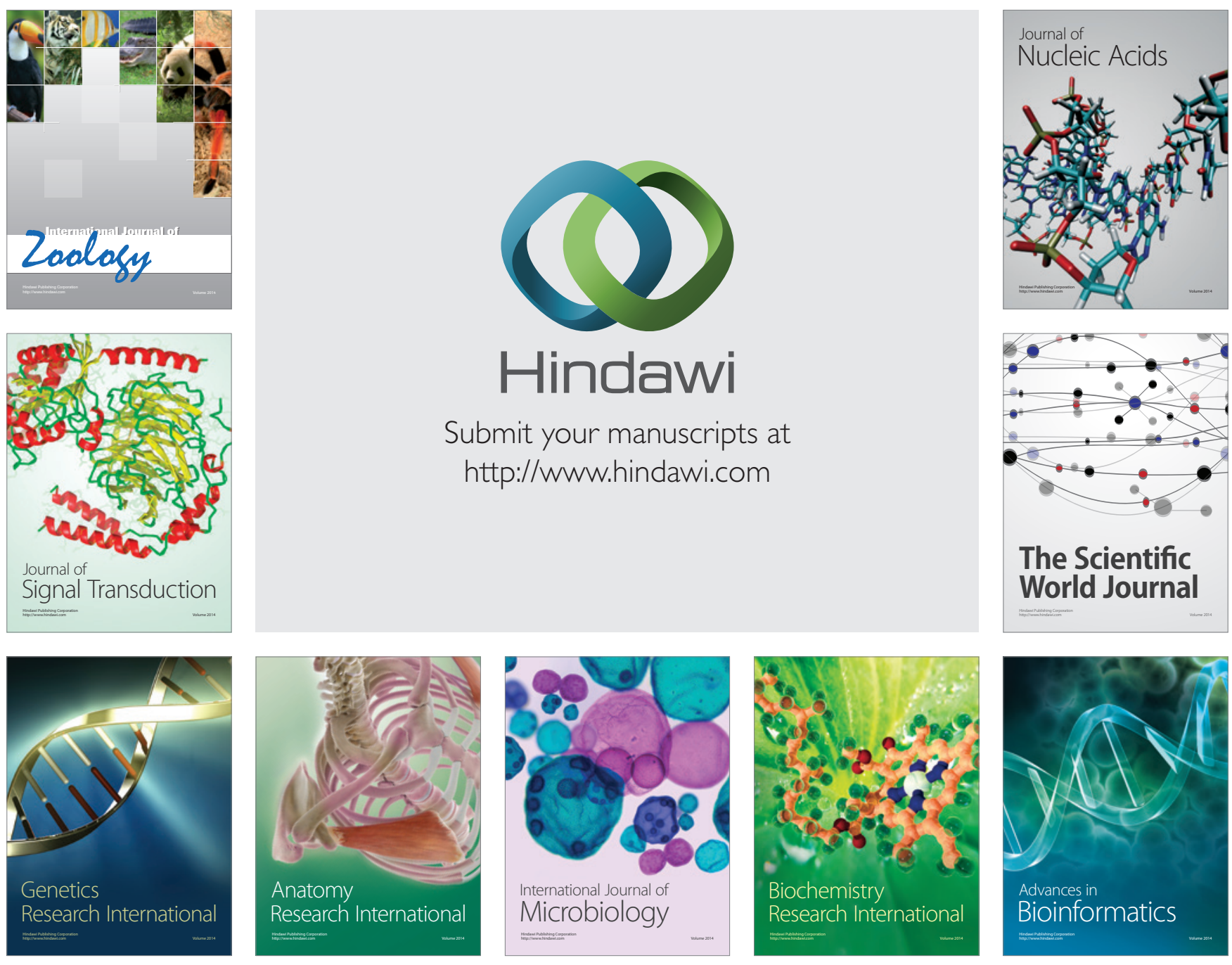

The Scientific World Journal
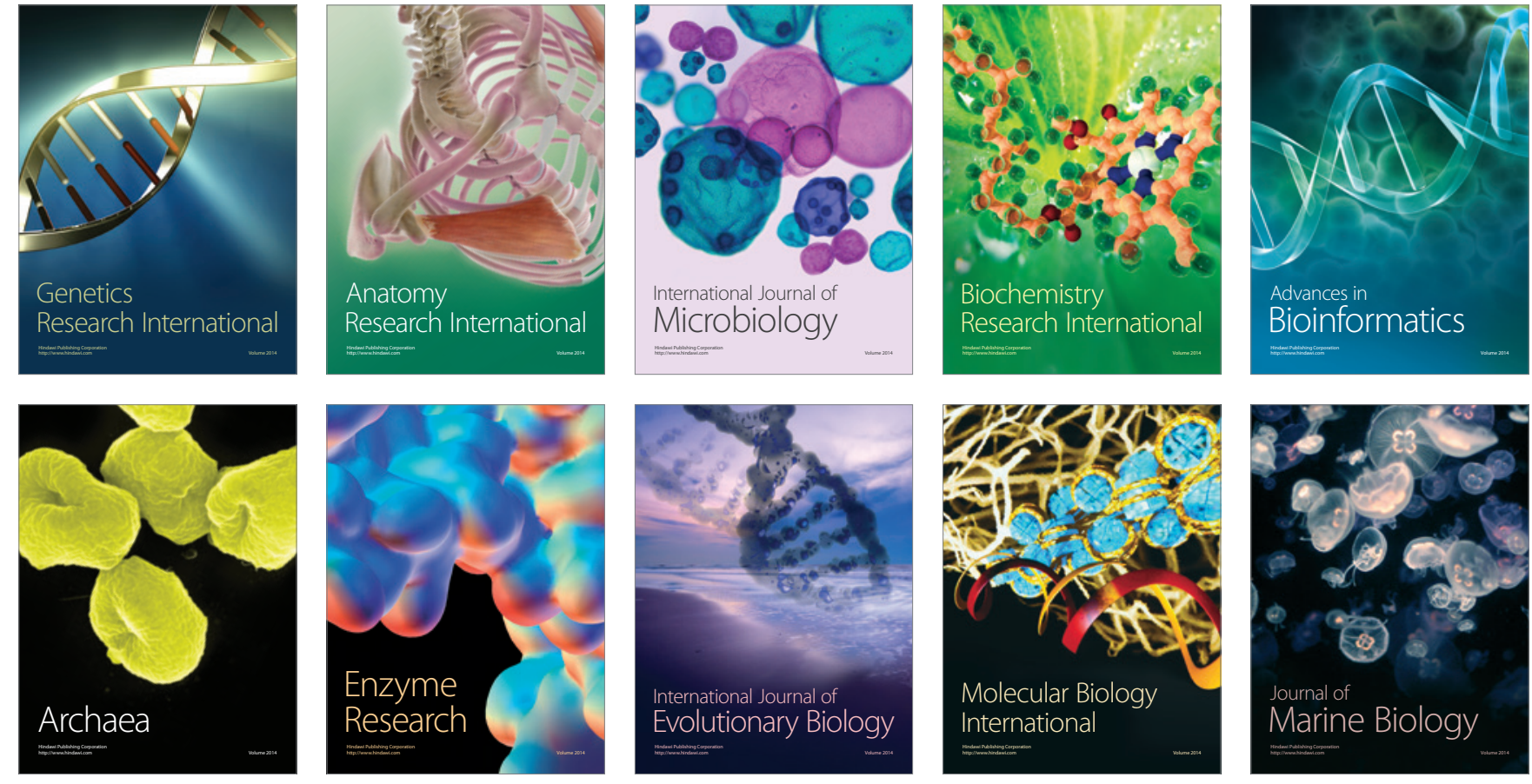